Check for updates

Cite this: New J. Chem., 2021, 45, 9462

Received 11th February 2021 Accepted 16th April 2021

DOI: 10.1039/d1nj00724f

rsc.li/njc

\section{Highly efficient diglycolamide-functionalized dendrimers for the sequestration of tetravalent actinides: solvent extraction and theoretical studies $\dagger$}

\author{
Parveen K. Verma, (D) ${ }^{a}$ Rajesh B. Gujar, ${ }^{a}$ Prasanta K. Mohapatra, (D) *a \\ Sk. Musharaf Ali, (D) ${ }^{b}$ Andrea Leoncini, ${ }^{c}$ Jurriaan Huskens ${ }^{(D)}{ }^{c}$ and \\ Willem Verboom (iD *c
}

\begin{abstract}
Two diglycolamide (DGA) functionalized poly(propylene imine)diaminobutane dendrimers, first generation (Gen I) and second generation (Gen II), termed as $L_{\mathbf{I}}$ and $L_{\mathbf{I I}}$, were used for the extraction of the tetravalent actinide ions $\mathrm{Np}^{4+}$ and $\mathrm{Pu}^{4+}$ from nitric acid medium. The metal ion extraction followed a 'solvation' type mechanism showing increasing metal ion extraction with increasing nitric acid concentration with species of the type: $M\left(N_{3}\right)_{4} \cdot \mathrm{L}\left(\mathrm{M}=\mathrm{Np}\right.$ or $\mathrm{Pu}$ ) with some contribution of $\mathrm{M}\left(\mathrm{NO}_{3}\right)_{4} \cdot 2 \mathrm{~L}$ for $\mathrm{Pu}$. $\mathrm{Pu}^{4+}$ formed much stronger complexes with both DGA-dendrimer ligands as compared with $\mathrm{Np}^{4+}$, as reflected in their two-phase extraction constants and higher $\Delta H$ values, attributed to its higher ionic potential. Binding of the metal ions was to one 'DGA pocket' in each of the dendrimers. The structure and bonding analysis was done on the basis of DFT studies.
\end{abstract}

\section{Introduction}

Diglycolamides are reported to be the most efficient extractants ${ }^{1}$ for 'Actinide Partitioning, ${ }^{2}$ which is considered relevant at the back end of the nuclear fuel cycle for the management of high level liquid waste (HLLW). ${ }^{3}$ TODGA $\left(N, N, N^{\prime}, N^{\prime}\right.$-tetra- $n$-octyl diglycolamide), the most studied diglycolamide (DGA) ligand, ${ }^{4}$ extracts trivalent actinide ions such as $\mathrm{Am}^{3+}$ from moderate concentrations of nitric acid (3-4 M) to a much greater extent than the $\mathrm{UO}_{2}{ }^{2+}$ ion, underlining its utility in HLLW management as compared with previously known and well studied ligands such as CMPO (carbamoylmethyl phosphine oxide), ${ }^{5}$ DIDPA (diisodecylphosphoric acid), ${ }^{6}$ TRPO (trialkylphosphine oxide) ${ }^{7}$ and even malonamides such as DMDOHEMA ( $N, N^{\prime}$-dimethyl- $N, N^{\prime}$ dioctylhexylethoxy malonamide) ${ }^{8}$ which extracts the $\mathrm{UO}_{2}{ }^{2+}$ ion to a much larger extent than the $\mathrm{Am}^{3+}$ ion. In view of the higher potential of TODGA for the extraction of minor actinide ions such

\footnotetext{
${ }^{a}$ Radiochemistry Division, Bhabha Atomic Research Centre, Mumbai 400085 , India. E-mail: mpatra@barc.gov.in

${ }^{b}$ Chemical Engineering Division, Bhabha Atomic Research Centre, Mumbai 400 085, India

${ }^{c}$ Laboratory of Molecular Nanofabrication, MESA + Institute for Nanotechnology, University of Twente, P.O. Box 217, 7500 AE Enschede, The Netherlands.

E-mail:w.verboom@utwente.nl

$\dagger$ Electronic supplementary information (ESI) available: Oxidation state adjustment; derivation extraction equilibrium constant; DFT data. See DOI: 10.1039/ d1nj00724f
}

as $\mathrm{Am}^{3+}$, several of 'hot' counter-current extraction studies have been performed by various research groups. ${ }^{9}$

Recently, attempts have been made to synthesize ligands with multiple DGA groups where DGA moieties have been grafted to suitable scaffolds such as calix[4]arene,$^{10}$ pillar[5]arene, ${ }^{11}$ TREN-based tripodals ${ }^{12}$ or even a planar scaffold such as benzene. ${ }^{13}$ We have recently reported poly(propylene imine) diaminobutane dendrimers containing DGA groups with very interesting results where the distribution ratio $(D)$ values for $\mathrm{Am}^{3+}$ ion with the generation zero (Gen 0$)$ dendrimer $(D \approx 0.1)$ increased by over 2 and 3 orders of magnitude when Gen I and Gen II dendrimers ( $\mathbf{L}_{\mathbf{I}}$ and $\mathbf{L}_{\mathbf{I I}}$, respectively; Fig. 1) were used under identical conditions. ${ }^{14}$ However, apart from our results on the extraction of the $\mathrm{Am}^{3+}$ ion, these DGA-functionalized dendrimers have been practically unexplored for the extraction of other important actinides present in HLLW.

Sasaki et al., in their first paper on the extraction of actinide using TODGA, reported a much larger extraction of $\mathrm{Np}^{4+}$ and $\mathrm{Pu}^{4+}$ than that of $\mathrm{Am}^{3+} .{ }^{4 a}$ It is understood that $\mathrm{Pu}$ produced during reactor operations (major constituent: ${ }^{239} \mathrm{Pu} ; t_{1 / 2}: 24100$ year) exists in a quite significant concentrations in the HLLW from PUREX (Plutonium Uranium Redox Extraction) losses. Similarly, the concentration of $\mathrm{Np}$, another activation product, in the HLLW of PWR origin (burn up: $33000 \mathrm{MWd}$ per T) is $c a$. $0.067 \mathrm{mg} \mathrm{g}^{-1},{ }^{15}$ which is mainly due to ${ }^{237} \mathrm{~Np}\left(t_{1 / 2}: 2.1 \times 10^{6}\right.$ year $)$. As per the 'Actinide Partitioning' scheme of safe management of HLLW, it is required to separate the long-lived radionuclides such 
as $\mathrm{Pu}$ and Np from the HLLW for their subsequent transmutation in high flux reactors or in accelerator driven sub-critical system (ADSS). ${ }^{16}$ Apart from this, ${ }^{237} \mathrm{~Np}$, if recovered from the HLLW can be used for the production of ${ }^{238} \mathrm{Pu}$ (power density: 0.57 Watt $\left.\mathrm{g}^{-1}\right)^{17}$ by neutron activation for its application in power sources. In view of these facts, it is of great relevance to study the extraction behaviour of $\mathrm{Np}^{4+}$ and $\mathrm{Pu}^{4+}$ ions using highly efficient multiple DGA extractants such as the DGA-functionalized dendrimers $\mathbf{L}_{\mathbf{I}}$ and $\mathbf{L}_{\mathbf{I}}$. To our knowledge, so far there is no report available on the extraction of $\mathrm{Pu}^{4+}$ and $\mathrm{Np}^{4+}$ using these DGA-functionalized dendrimers.

Our previous studies on the complexation of trivalent lanthanide/actinide ions with these ligands suggested unusual binding with the $\mathrm{ML}_{2}$ type of species, which cannot be easily explained on the basis of the coordination of DGA groups from two ligands. There was an issue of isolating the complexes due to the formation of pasty masses with the dendrimer ligands. Moreover, with their $\mathrm{Np}$ and $\mathrm{Pu}$ complexes, which have very high specific activities, it was not possible to work due to the large radioactivity associated with the complexes. Therefore, it was thought of interest to investigate the bonding of the tetravalent metal ions with the DGA-functionalized dendrimers $\mathbf{L}_{\mathbf{I}}$ and $\mathbf{L}_{\mathbf{I I}}$ by DFT computational studies.

The present study involves the extraction of $\mathrm{Np}^{4+}$ and $\mathrm{Pu}^{4+}$ ions using the Gen I and Gen II DGA-functionalized dendrimers $\mathbf{L}_{\mathbf{I}}$ and $\mathbf{L}_{\mathbf{I I}}$. After obtaining the nature of the extracted species by solvent extraction, an attempt was made to understand the bonding of the complexes with the DGA groups by DFT. The studies also include the determination of thermodynamic parameters for getting an idea about the extraction/complexation process.

\section{Results and discussion}

\section{Solvent extraction studies}

The DGA-functionalized poly(propylene imine) diaminobutane dendrimers $\mathbf{L}_{\mathbf{I}}$ (Gen I) and $\mathbf{L}_{\mathbf{I I}}$ (Gen II) (Fig. 1) were evaluated for the solvent extraction of the tetravalent actinides $\mathrm{Np}(\mathrm{IV})$ and

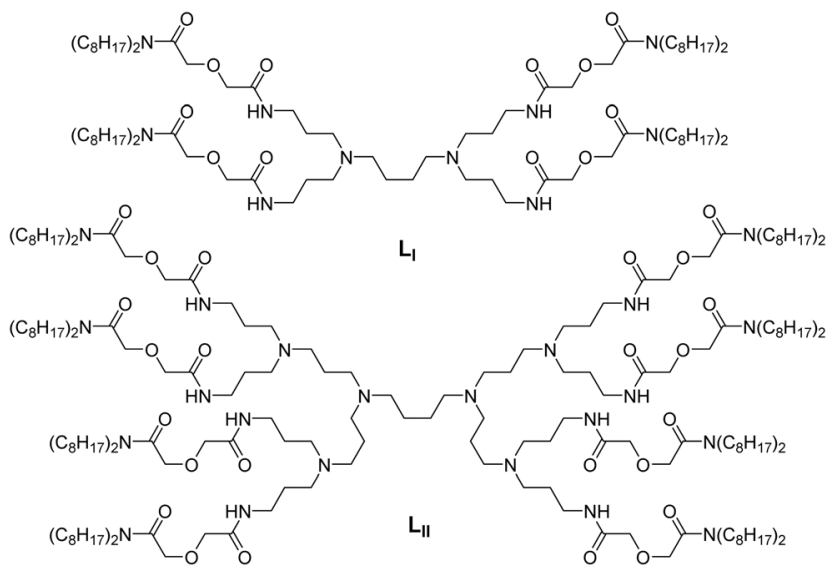

Fig. 1 Structure of the diglycolamide (DGA) functionalized poly(propylene imine) diaminobutane dendrimers, generation $1\left(\mathbf{L}_{\mathbf{l}}\right)$ and generation $2\left(L_{11}\right)$.
$\mathrm{Pu}(\mathrm{Iv})$ from dilute to moderate nitric acid solutions. The extraction studies were carried out with $0.1 \mathrm{mM}$ ligand in 5\% IDA (isodecanol) $+n$-dodecane diluent due to the poor solubility of these ligands in pure $n$-dodecane. ${ }^{1}$

The uptake of water and nitric acid was studied both in the absence and the presence of the extractants. The results indicated about $1 \%$ extraction of the acid by the solvent (diluent + ligand) (Table S1, ESI $\dagger$ ). The extraction of nitric acid by alcohols is well known $^{18}$ and the extracted acid forms the (extractant-nitric acid) complex as per the following equilibrium reaction.

$$
x \mathrm{HNO}_{3, \mathrm{aq}}+y \mathrm{~L}_{\mathrm{org}} \stackrel{K_{\mathrm{H}}}{\rightleftharpoons}\left(\mathrm{HNO}_{3}\right)_{x} \cdot y \mathrm{~L}_{\mathrm{org}}
$$

An attempt was made to determine the $K_{\mathbf{H}}$ values for both $\mathbf{L}_{\mathbf{I}}$ and $\mathbf{L}_{\mathbf{I I}}$. The acid-base titration studies were not very conclusive due to the very small changes obtained with the ligand solutions vis-à-vis the blank (diluent mixture) as the changes were less than the experimental errors (Fig. S2; ESI $\dagger$ ). On the other hand, FT-IR measurements clearly showed a shift in the carbonyl band of the ligand solutions after equilibration with $3 \mathrm{M} \mathrm{HNO}_{3}$ (Fig. S3 and $\mathrm{S} 4$; ESI $\dagger$ ). The $K_{\mathrm{H}}$ values were, therefore, obtained using the FTIR data (details are given in the ESI $\dagger$ ) and were found to be 0.27 $( \pm 0.05)$ and $0.32( \pm 0.06)$ for $\mathbf{L}_{\mathbf{I}}$ and $\mathbf{L}_{\text {II }}$, respectively which were very close to the reported values for other DGA ligands. ${ }^{19,20}$

The presence of 5\% iso-decanol in the diluent mixture was responsible for the extraction of $0.05 \%$ ( $c a .27 .8 \mathrm{mM}$ ) of water into the organic phase as well (Table S1, ESI $\dagger$ ) and might make the metal ions highly hydrated (in view of the tracer concentrations involved resulting in very high water to metal ion ratios) unless the DGA groups can replace them by strong complex formation (vide infra).

The extraction of both the tetravalent metal ions was fast with both the ligands in this diluent and the extraction equilibrium was attained in 15-20 minutes (Fig. S1; ESI $\dagger$ ). We have also observed fast extraction kinetics for the trivalent actinides using the same ligand system. ${ }^{14}$

The extraction of both $\mathrm{Np}$ (Iv) and $\mathrm{Pu}$ (Iv) was also studied as a function of the feed acidity from $0.5 \mathrm{M}$ to $6 \mathrm{M} \mathrm{HNO}_{3}$. Acid concentrations $<0.5 \mathrm{M}$ were not used as the metal ions can be hydrolyzed. ${ }^{21}$ The extraction of $\mathrm{Np}(\mathrm{Iv}) / \mathrm{Pu}(\mathrm{Iv})$ increased with the increase in the feed acidity for both ligands (Fig. 2a). The extraction of both the metal ions was found to be highly efficient as ca. $90 \%$ or higher extraction was observed even with $1 \times 10^{-4} \mathrm{M}$ ligand solutions. When compared with the extraction of the $\mathrm{Am}^{3+}$ ion, ${ }^{14}$ the extraction of $\mathrm{Pu}^{4+}$ is comparable, albeit, with almost 10 times lower concentration of the ligands. Also, while using a $10 \mu \mathrm{M}$ solution of the ligand $\mathbf{L}_{\mathbf{I I}},>90 \%$ extraction of $\mathrm{Pu}(\mathrm{Iv})$ was possible. This suggests that the DGAbased dendrimer ligands $\mathbf{L}_{\mathbf{I}}$ and $\mathbf{L}_{\mathbf{I I}}$ are highly promising for applications in radioactive waste management.

The general equilibrium for the extraction of $\mathrm{M}(\mathrm{IV})$ with $\mathrm{L}\left(\mathbf{L}_{\mathbf{I}} / \mathbf{L}_{\mathbf{I I}}\right)$ in $5 \%$ IDA $+n$-dodecane can be written as eqn (2):

$$
\mathrm{M}^{4+}{ }_{\text {aq }}+a \mathrm{~L}_{\mathrm{f}, \text { org }}+b \mathrm{NO}_{3}{ }_{\text {aq }}^{-} \stackrel{K_{\mathrm{ex}}}{\rightleftharpoons} \mathrm{M}\left(\mathrm{NO}_{3}\right)_{b} \cdot a \mathrm{~L}_{\text {org }}
$$

where $\mathrm{M}$ is $\mathrm{Np}(\mathrm{Iv}) / \mathrm{Pu}(\mathrm{IV}), \mathrm{L}_{\text {f,org }}$ is the 'free' form (which does not exist as the (extractant-nitric acid) complex) of either $\mathbf{L}_{\mathbf{I}}$ or $\mathbf{L}_{\mathbf{I I}}$ and 

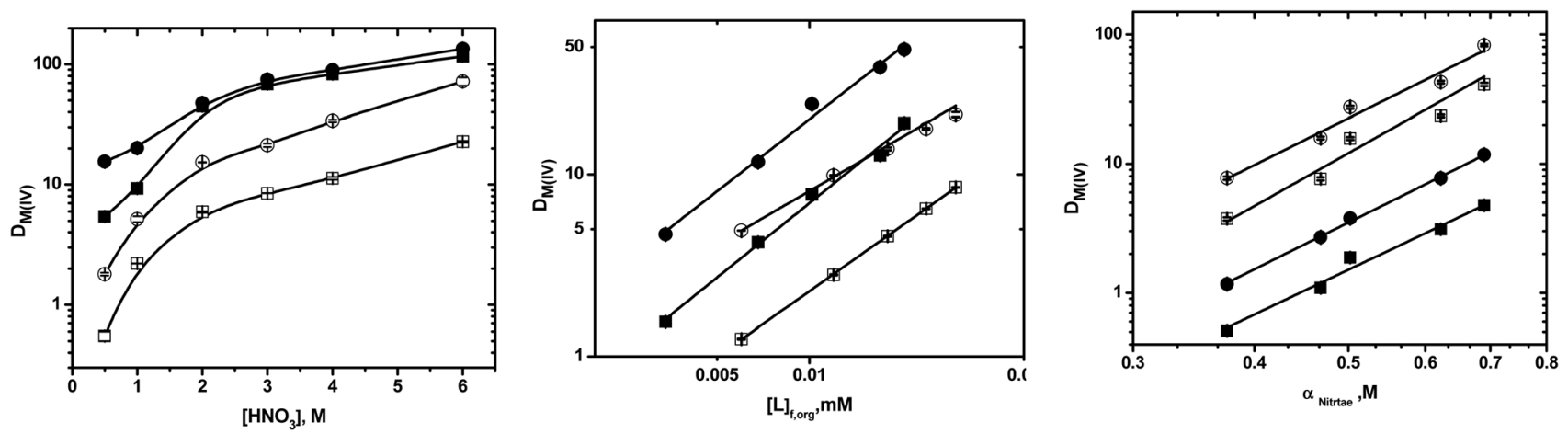

Fig. 2 The extraction of $\mathrm{Np}$ (IV) (open symbols) and Pu(Iv) (closed symbols) as a function of (left) varying acidity using $1 \times 10^{-4} \mathrm{M}$ ligand solutions; (center)

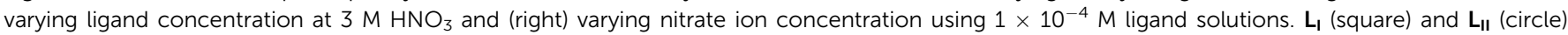
dissolved in 5\% IDA+ $n$-dodecane; T: $298 \mathrm{~K}$.

$K_{\text {ex }}$ is the two-phase extraction constant. The subscripts 'aq' and 'org' indicate the species present in the aqueous and organic phases, respectively. The $K_{\mathrm{H}}$ values of the ligands, as mentioned above, were used to calculate the $\mathrm{L}_{\mathrm{f}, \text { org }}$ concentrations. Although an increase in the $D_{\mathrm{M}(\mathrm{v})}$ was observed for both ligands, the relative change in the $D_{\mathrm{M}(\mathrm{vv})}$ differed depending on the ligand. The $\mathrm{Np}$ (rv) extraction showed a steady increase with the aqueous phase acidity. The extraction of the metal ions involves the replacement of the coordinated water molecules from the inner-sphere with the DGA groups. The extraction by the DGA-dendrimer $\mathbf{L}_{\mathbf{I I}}$ remained superior to that of $\mathbf{L}_{\mathbf{I}}$ over the whole acidity range, whereas for the $\mathrm{Pu}(\mathrm{Iv})$ extraction the change in the $D_{\mathrm{Pu}(\mathrm{rv})}$ with different ligands was appreciable at lower acidity and merges at higher acidity. The higher extraction by $\mathbf{L}_{\mathbf{I I}}$ can either be attributed to the higher number of coordinating sites available for complexation or may be due to the higher lipophilicity of the extracted $\mathrm{M}(\mathrm{Iv})-\mathbf{L}_{\mathbf{I I}}$ complex compared with the $\mathbf{M}(\mathrm{rv})-\mathbf{L}_{\mathbf{I}}$ complex. The steady increase in the $D_{\mathrm{M}(\mathrm{v})}$ with the aqueous feed acidity suggest the solvation mechanism for the extraction of the tetravalent actinides with both ligands in $5 \%$ IDA $+n$-dodecane (Fig. 2a).

The extraction equilibrium constant for the present system can be given by eqn (3):

$$
K_{\mathrm{ex}}=\frac{\left[\mathrm{M}\left(\mathrm{NO}_{3}\right)_{b} \cdot a \mathrm{~L}\right]_{\mathrm{org}}}{\left[\mathrm{M}^{4+}\right]_{\mathrm{aq}}\left[\mathrm{NO}_{3}\right]_{\mathrm{aq}}^{b}[\mathrm{~L}]_{\mathrm{f}, \mathrm{org}}^{a} \cdot \gamma_{\mathrm{M}^{4+}} \cdot \gamma_{\mathrm{NO}_{3}}^{b} \cdot \gamma_{\mathrm{L}}^{a}}
$$

where the square brackets represent the concentration of each species therein and $\gamma$ is the activity coefficient for the given species. Assuming the activity constant for various species remains constant for the given concentration of $\mathrm{L}$ and $\mathrm{NO}_{3}{ }^{-}$, and its temperature dependence is very small, we can write eqn (4), obtained under the above assumptions:

$$
K_{\mathrm{ex}}=\frac{\left[\mathrm{M}\left(\mathrm{NO}_{3}\right)_{b} \cdot a \mathrm{~L}\right]_{\mathrm{org}}}{\left[\mathrm{M}^{4+}\right]_{\mathrm{aq}}\left[\mathrm{NO}_{3}\right]_{\mathrm{aq}}^{b}[\mathrm{~L}]_{\mathrm{f}, \mathrm{org}}^{a}}
$$

After a series of mathematical manipulations and approximations (ESI $\dagger$ ), one can obtain the linearized form of the equation, containing the apparent extraction equilibrium constant $\left(K_{\mathrm{ex}}^{\prime}\right)$, as:

$$
\log D_{\mathrm{M}}=\log K_{\mathrm{ex}}^{\prime}+a \log [\mathrm{L}]_{\mathrm{f}, \text { org }}+b \log \left[\mathrm{NO}_{3}^{-}\right]_{\mathrm{aq}}
$$

where $K_{\text {ex }}^{\prime}$ is defined as the ratio of $K_{\text {ex }}$ to $K_{\text {Nit }}$ (the constant containing the nitrate ion complexation part; ESI $\dagger$ ).

Eqn (5) gives the linear dependence of $\log D_{\mathrm{M}}$ with the nitrate ion and ligand concentrations at a given temperature. All experiments were carried out at $298 \mathrm{~K}$ for the sake of convenience. The stoichiometry of the extracted complex in the organic phase can be found if the values of ' $a$ ' and ' $b$ ' are known from eqn (5). The values of ' $a$ ' and ' $b$ ' can easily be determined by evaluating $D_{\mathrm{M}}$ at varying concentrations of the free ligand in the organic phase at a fixed nitrate ion concentration and vice versa.

\section{Stoichiometry of the extracted species}

The stoichiometry of the extracted complexes in the solvent extraction of tetravalent actinides by $\mathbf{L}_{\mathbf{I}} / \mathbf{L}_{\mathbf{I I}}$ in $5 \%$ IDA $+n$-dodecane was determined by the conventional slope analysis method. ${ }^{14,22}$ To obtain the value of ' $a$ ' from eqn (5), the concentration of the ligands $\left(\mathbf{L}_{\mathbf{I}}\right.$ or $\left.\mathbf{L}_{\mathbf{I I}}\right)$ was varied at a fixed acidity, i.e. $3 \mathrm{M} \mathrm{HNO}_{3}$, and the distribution ratio values of $\mathrm{Np}(\mathrm{Iv})$ and $\mathrm{Pu}(\mathrm{Iv})$ were measured. The equilibrium free ligand concentration was assumed to be equal to the initial free ligand concentration as the amount of ligand involved in the complexation is very small due to very small concentrations of the metal ions used in the present study ([Np]: $10^{-12} \mathrm{M}$ and $\left.[\mathrm{Pu}]: 10^{-6} \mathrm{M}\right)$. The $\log D_{\mathrm{M}(\mathrm{vv})} v$ s. $\log [\mathrm{L}]_{\mathrm{f}, \mathrm{org}}\left(\mathrm{L}_{\mathrm{L}} \mathbf{L}_{\mathbf{I}} / \mathbf{L}_{\mathbf{I I}}\right)$ gives average slope values of $1.20 \pm 0.17$ for all the systems (Fig. 2b) suggesting the involvement of one ligand in the extracted species. The slope values for the individual systems are given in Table S2 (ESI $\dagger$ ). However, while the extracted species for $\mathrm{Np}(\mathrm{Iv})$ resulted in slope values very close to 1 , those for Pu(rv) yielded slopes close to 1.3 , suggesting predominantly ML-type species with some contributions of $\mathrm{ML}_{2}$. Similarly, the nitrate ion concentration variation experiments were done at a fixed $\mathrm{HNO}_{3}$ concentration of $0.5 \mathrm{M}$ (in order to prevent hydrolysis of the metal ions) ${ }^{21}$ at a fixed ligand concentration (Fig. 2c). Since the concentration of the $\mathrm{NaNO}_{3}$ used in the nitrate ion concentration variation experiments is large (0.5-3 $\left.\mathrm{M} \mathrm{NaNO}_{3}\right)$, the activities of the $\mathrm{NO}_{3}{ }^{-}$ $\left(a\left(\mathrm{NO}_{3}{ }^{-}\right)\right)$ions were calculated using the activity coefficient 
reported in literature and used for the $\log a\left(\mathrm{NO}_{3}{ }^{-}\right)$ calculations. ${ }^{23,24} \log \mathrm{D}_{\mathrm{M}(\mathrm{rv})}$ vs. $\log a\left(\mathrm{NO}_{3}{ }^{-}\right)$plots were obtained for all the studied systems. Slope analysis of the linear log-log plot gives an average value of $3.70 \pm 0.08$ for all the systems, suggesting extraction of neutral $\mathrm{M}\left(\mathrm{NO}_{3}\right)_{4} \mathrm{~L}$ ( $\mathrm{L}: \mathbf{L}_{\mathbf{I}}$ or $\left.\mathbf{L}_{\mathbf{I I}}\right)$ species for both the tetravalent metal ions by $\mathbf{L}_{\mathbf{I}}$ or $\mathbf{L}_{\mathbf{I I}}$ dissolved in $5 \%$ IDA + $n$-dodecane (Fig. 2c). The formation of a similar neutral complex of type $\mathrm{Ln}(\mathrm{III})\left(\mathrm{NO}_{3}\right)_{3} \mathrm{~L}\left(\mathrm{~L}=\mathbf{L}_{\mathbf{I}}\right.$ or $\left.\mathbf{L}_{\mathbf{I I}}\right)$, was also obtained for the extraction of trivalent metal ions by these ligands. Although, it can be expected, that the higher number of DGA arms in $\mathbf{L}_{\mathbf{I I}}$ can bind more metal ions giving a higher $\mathrm{M}: \mathrm{L}$ ratio. However, the slope variation experiments suggested the formation of $1: 1 \mathrm{M}: \mathrm{L}$ ratio complexes in the solvent extraction. The extraction of higher $\mathrm{M}: \mathrm{L}$ complexes, such as 2:1 or higher, may be hindered due to the poor solubility of such polar complexes, with eight $\mathrm{NO}_{3}{ }^{-}$ions (to maintain neutrality) in the $2: 1$ complex, in the marginally polar $5 \%$ IDA $+n$-dodecane medium. ${ }^{21}$

\section{Thermodynamic parameters of extraction}

The extraction of the $\mathrm{M}(\mathrm{IV})$ by $\mathbf{L}_{\mathbf{I}} / \mathbf{L}_{\mathbf{I I}}$ dissolved in $5 \%$ IDA + $n$-dodecane was studied at different temperatures to understand the thermodynamics of the extraction process. The extraction of $\mathrm{Pu}(\mathrm{IV})$ and $\mathrm{Np}(\mathrm{Iv})$ was carried out at $1 \times 10^{-5} \mathrm{M}$ and $1 \times 10^{-4} \mathrm{M}$ $\mathbf{L}_{\mathbf{I}} / \mathbf{L}_{\mathbf{I I}}$ in $5 \%$ IDA+ $n$-dodecane, respectively. This was required to obtain reasonably good $D$ values for $\mathrm{Pu}(\mathrm{Iv})$, as the values were very high with $1 \times 10^{-4} \mathbf{M} \mathbf{L}_{\mathbf{I}} / \mathbf{L}_{\mathbf{I I}}$. The $D$ values for both $\mathrm{Np}$ (Iv) and $\mathrm{Pu}(\mathrm{Iv})$ were found to decrease with increasing temperature, suggesting the exothermic nature of the extraction process (Fig. 3). The activity coefficient values for all the species in eqn (2) were assumed to be unity, except for $\mathrm{NO}_{3}{ }^{-}$ions, due to the very small concentrations of the ligands $\left(\leq 10^{-4} \mathrm{M}\right)$ and the metal ions ([Np]: $10^{-12} \mathrm{M}$ and $\left.[\mathrm{Pu}]: 10^{-6} \mathrm{M}\right) \cdot{ }^{23-25}$ Assuming that the activity of $\mathrm{NO}_{3}{ }^{-}$and the free ligands remains unchanged with the varying temperature and the value of $K_{\mathrm{Nit}}$ (eqn (S5) in ESI $\dagger$ ) also does not change significantly under the studied temperature range, eqn (6) (the Gibbs-Helmholtz equation and $\left.\Delta G=-R T \ln K_{\mathrm{ex}}{ }^{\prime}\right)$ can be used to calculate the enthalpy change

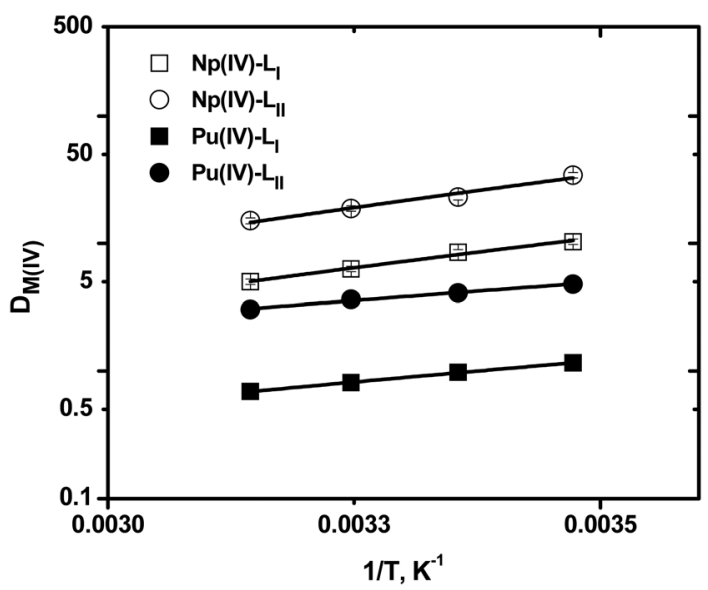

Fig. 3 Effect of temperature on the extraction of $\mathrm{Np}$ (IV) (open symbols)

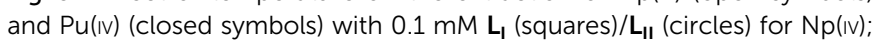
and $0.01 \mathrm{mM} \mathrm{L}_{1}$ (squares) $/ \mathrm{L}_{\text {II }}$ (circles) for $\mathrm{Pu}(\mathrm{IV})$ at $3 \mathrm{M} \mathrm{HNO}_{3}$.
$(\Delta H)$ in the extraction of $\mathrm{M}(\mathrm{Iv})$ by the different ligands at $3 \mathrm{M}$ $\mathrm{HNO}_{3} \cdot{ }^{22,26-28}$

$$
\log K_{\mathrm{ex}}^{\prime}=-\left(\Delta H_{\mathrm{O}} / 2.303 R\right)(1000 / T)+\left(\Delta S_{\mathrm{O}} / 2.303 R\right)
$$

The $\log K_{\mathrm{ex}}^{\prime} v s .1 / T$ plot gives a straight line, and the slope values were used to calculate the $\Delta H$ values (in $\mathrm{kJ} \mathrm{mol}^{-1}$ ) using eqn (7):

$$
\Delta H_{\mathrm{O}}=-2.303 R \times \text { slope }
$$

where $R$ is the universal gas constant. The slope values are included in Table S2 (ESI $\dagger$ ) and which can be used for the calculation of $\Delta H_{\mathrm{O}}$.

The values of $K_{\text {ex }}$ for the extraction of $\mathbf{M}(\mathrm{Iv})$ by $\mathbf{L}_{\mathbf{I}} / \mathbf{L}_{\mathbf{I I}}$ were calculated at $3 \mathrm{M} \mathrm{HNO}_{3}$ as mentioned in the ESI $\dagger$ (using eqn (S4)). For the computation of $K_{\mathrm{ex}}{ }^{\prime}$, the value of $K_{\mathrm{Nit}}$ was taken as 40.5 and 105 for $\mathrm{Np}$ (Iv) and $\mathrm{Pu}(\mathrm{IV})$, respectively, at $3 \mathrm{M} \mathrm{HNO}_{3} \cdot{ }^{29-31}$ The value of 2.78 was used for the $\left[\mathrm{NO}_{3}{ }^{-}\right]$, calculated using a $K_{\mathrm{a}}$ value of 23 for the dissociation of $\mathrm{HNO}_{3}{ }^{28}$ The values of the thermodynamic parameters $\Delta G, \Delta H_{\mathrm{O}}$ and $T \Delta S$ were calculated as mentioned above. These values, together with the $K_{\text {ex }}{ }^{\prime}$ values, are summarized in Table 1.

The overall enthalpy change $\left(\Delta H_{\mathrm{O}}\right)$ during the solvent extraction of the tetravalent actinides can be viewed as the sum of the enthalpies of the different processes such as dehydration of the actinides $\left(\Delta H_{\mathrm{W}}\right)$, complexation of the actinides with the ligands $\left(\Delta H_{\mathrm{C}}\right)$ and dissolution of the neutral $\mathrm{M}\left(\mathrm{NO}_{3}\right)_{4} \cdot \mathrm{L}$ complex into the molecular solvent $\left(\Delta H_{\mathrm{D}}\right)$. The overall magnitude and the sign of $\Delta H_{\mathrm{O}}$ depends on the contributions of all three, i.e. the $\Delta H_{\mathrm{W}}, \Delta H_{\mathrm{C}}$ and $\Delta H_{\mathrm{D}}$ terms.

$$
\Delta H_{\mathrm{O}}=\Delta H_{\mathrm{W}}+\Delta H_{\mathrm{D}}+\Delta H_{\mathrm{C}}
$$

Although the $\Delta H_{\mathrm{W}}$ term may be positive (an endothermic process) for the dehydration of both $\mathrm{Pu}(\mathrm{Iv})$ and $\mathrm{Np}$ (Iv) as it is an energy intensive process, it may be more positive for the former because of its high ionic potential. The higher positive value of $\Delta H_{\mathrm{W}}$ for $\mathrm{Pu}(\mathrm{Iv})$ may be compensated by its higher negative value of $\Delta H_{\mathrm{C}}$ compared with $\mathrm{Np}$ (Iv). The $\Delta H_{\mathrm{D}}$ values for the dissolution of the neutral $\mathrm{M}\left(\mathrm{NO}_{3}\right)_{4} \cdot \mathrm{L}$ complexes must be very similar as the size of the complexes formed is predominantly decided by the size and number of associated ligands, which are the same for both ions. The Gibbs free energy $(\Delta G)$ for $\mathrm{Pu}(\mathrm{Iv})$ extraction with both the ligands was found to be higher than that for $\mathrm{Np}$ (Iv) extraction due to its higher extraction equilibrium constant (Table 1). This higher value of the $\Delta G$ suggests a

Table 1 Thermodynamic parameters for the extraction of $\mathrm{Np}$ (Iv) and $\mathrm{Pu}$ (Iv) by $L_{1} / L_{\text {II }}$ in $5 \%$ IDA $+n$-dodecane from $3 \mathrm{M} \mathrm{HNO}_{3}$ at $298 \mathrm{~K}$

\begin{tabular}{lllll}
\hline Ligand & $\Delta G\left(\mathrm{~kJ} \mathrm{~mol}^{-1}\right)$ & $\Delta H_{0}\left(\mathrm{~kJ} \mathrm{~mol}^{-1}\right)$ & $T \Delta S\left(\mathrm{~kJ} \mathrm{~mol}^{-1}\right)$ & $\log K_{\mathrm{ex}}^{\prime}$ \\
\hline $\mathrm{Np}(\mathrm{IV})$ & & & & \\
$\mathbf{L}_{\mathbf{I}}$ & $-27.14 \pm 0.06$ & $-18.76 \pm 1.17$ & $8.38 \pm 0.50$ & $4.76 \pm 0.01$ \\
$\mathbf{L}_{\mathrm{II}}$ & $-29.62 \pm 0.09$ & $-20.53 \pm 0.79$ & $9.09 \pm 0.24$ & $5.19 \pm 0.15$ \\
& & & & \\
$\mathrm{Pu}(\mathrm{IV})$ & & & & \\
$\mathbf{L}_{\mathbf{I}}$ & $-40.40 \pm 0.08$ & $-11.29 \pm 0.85$ & $29.11 \pm 0.39$ & $7.08 \pm 0.04$ \\
$\mathbf{L}_{\text {II }}$ & $-40.62 \pm 0.10$ & $-13.25 \pm 0.29$ & $27.37 \pm 0.21$ & $7.12 \pm 0.18$
\end{tabular}


stronger interaction of $\mathrm{Pu}(\mathrm{Iv})$ with the ligands. The enthalpy contribution to the overall $\Delta G$ value is small for the extraction of $\mathrm{Pu}(\mathrm{Iv})$ as compared with $\mathrm{Np}$ (Iv) for both the ligands, whereas the reverse is true for the $\Delta S$ value. The higher contribution of $\Delta S$ in the case of $\mathrm{Pu}(\mathrm{IV})$ may be attributed to the release of coordinated water molecules from the primary and secondary hydration spheres and the 'distortion' created in the organic phase due the dissolution of the extracted complex, both adding to the entropy increase.

\section{Back extraction studies}

The back extraction of the tetravalent actinides $\mathrm{Np}$ (Iv) and $\mathrm{Pu}$ (Iv) by adjusting the acidity is difficult, hence aqueous complexing agents such as oxalic acid and HEDTA (hydroxyethyl ethylenediamine triacetic acid) were used. ${ }^{22}$ The organic phase with extracted $\mathbf{M}$ (Iv) was equilibrated with an aqueous phase containing 0.1 M HEDTA or $0.5 \mathrm{M}$ oxalic acid in $0.05 \mathrm{M} \mathrm{HNO}_{3}$. The quantitative back extraction of the tetravalent actinides $\mathrm{Np}$ (Iv) and $\mathrm{Pu}(\mathrm{Iv})$ could be achieved by $0.1 \mathrm{M}$ HEDTA in $0.05 \mathrm{M} \mathrm{HNO}_{3}$ compared with the $0.5 \mathrm{M}$ oxalic acid in $0.05 \mathrm{M} \mathrm{HNO}_{3}$ (Table 2).

\section{Radiolytic stability studies}

The liquid-liquid extraction process employed in the nuclear industry is always accompanied by the associated irradiation dose. It is desirable to have a good radiolytic stability of the extraction system. Therefore, the solvent system was irradiated with ${ }^{60}$ Co to a cumulative dose of $300 \mathrm{kGy}$. Subsequently, the extraction of the $\mathbf{M}(\mathrm{Iv})$ was done with the irradiated solvents from $3 \mathrm{M} \mathrm{HNO}_{3}$ solution. The $D_{\mathrm{M}(\mathrm{iv})}$ values decreased drastically upon irradiation, suggesting the poor radiation stability of the present systems at higher irradiation doses (Table 3).

\section{DFT studies}

Structural parameters. The minimum energy structures of the complexes of $\mathrm{Np}^{4+}$ towards the dendrimer ligands of generations 1 and $2\left(\mathbf{L}_{\mathbf{I}}\right.$ and $\left.\mathbf{L}_{\mathbf{I I}}\right)$ are displayed in Fig. 4. An analogous exercise

Table 2 Back extraction (\%) of Np(Iv) and Pu(Iv) using 0.1 M HEDTA and $0.5 \mathrm{M}$ oxalic acid (OA) in $0.05 \mathrm{M} \mathrm{HNO}_{3}$; organic phase: $0.1 \mathrm{mM} \mathrm{L}_{\mathbf{1}} / \mathrm{L}_{\| 1}$ in $5 \%$ IDA + n-dodecane; $T: 298 \mathrm{~K}$

\begin{tabular}{|c|c|c|c|c|}
\hline \multirow[b]{3}{*}{ Aqueous phase } & \multicolumn{4}{|c|}{$\%$ Back extraction } \\
\hline & \multicolumn{2}{|l|}{$\mathrm{Np}$} & \multicolumn{2}{|l|}{$\mathrm{Pu}$} \\
\hline & $\mathbf{L}_{\mathbf{I}}$ & $\mathbf{L}_{\text {II }}$ & $\mathbf{L}_{\mathbf{I}}$ & $\mathbf{L}_{\text {II }}$ \\
\hline HEDTA & $>99.9$ & 99.0 & 96.2 & 77.5 \\
\hline OA & 70.9 & 5.24 & 71.9 & 16.5 \\
\hline
\end{tabular}

Table 3 Effect of irradiation of the organic phase on the extraction efficiency of $\mathrm{Np}(\mathrm{IV})$ and $\mathrm{Pu}(\mathrm{IV})$ from $3 \mathrm{M} \mathrm{HNO}_{3}$; organic phase: $0.1 \mathrm{mM} \mathrm{L}_{\mathbf{1}}$ / $\mathrm{L}_{\text {II }}$ in $5 \%$ IDA $+n$-dodecane; $T: 298 \mathrm{~K}$

\begin{tabular}{llrlrl}
\hline & \multirow{2}{*}{$D_{\mathrm{Np}(\mathrm{IV})}$} & \multicolumn{2}{l}{$D_{\mathrm{Pu}(\mathrm{IV})}$} & \\
\cline { 2 - 3 } \cline { 5 - 6 } Dose $(\mathrm{kGy})$ & $\mathbf{L}_{\mathbf{I}}$ & \multicolumn{1}{c}{$\mathbf{L}_{\mathbf{I I}}$} & \multicolumn{1}{l}{$\mathbf{L}_{\mathbf{I}}$} & \multicolumn{1}{l}{$\mathbf{L}_{\mathbf{I I}}$} \\
\hline 0 & $8.49 \pm 0.02$ & $23.12 \pm 0.45$ & $68.38 \pm 3.84$ & $74.95 \pm 4.28$ \\
300 & $0.13 \pm 0.01$ & $0.16 \pm 0.01$ & $0.14 \pm 0.01$ & $0.03\left(<10^{-3}\right)$
\end{tabular}

was done for $\mathrm{Pu}^{4+}$ and the optimized structures are given in the ESI $\dagger$ (Fig. S5). In Fig. 4a, the $\mathrm{Np}^{4+}$ ion is coordinated to two DGA units and four monodentate nitrate ions leading to a decacoordinated metal ion, whereas in Fig. $4 \mathrm{~b}$, the $\mathrm{Np}^{4+}$ ion is coordinated to one DGA unit and four nitrate ions (two monodentate and two bidentate) leading to a nona-coordinated metal ion. The calculated structural parameters for the $\mathrm{Np}^{4+}$ ion complexes are presented in Table 4 while those for the $\mathrm{Pu}^{4+}$ complexes are given in the ESI $\dagger$ (Table S3). The $\mathrm{Np}-\mathrm{O}$ bond length for both the amidic ' $\mathrm{O}$ ' as well as the etheric ' $\mathrm{O}$ ' is longer than that of the corresponding $\mathrm{Np}-\mathrm{O}$ bond length of the upper rim complex. Further, the metal-oxygen bond distance with the amidic $\mathrm{O}$ is shorter than that with the ethereal $\mathrm{O}$ atom, indicating that the amidic $\mathrm{O}$ will give a stronger interaction than the ethereal $\mathrm{O}$ atom. It must be noted that the $\mathrm{Np}-\mathrm{O}$ bond length with nitrate $\mathrm{O}$ is shorter than that with the amidic $\mathrm{O}$. In addition, the Np-O bond distance with the monodentate nitrate ion is shorter than that with the bidentate nitrate ions. Concerning ligand $\mathbf{L}_{\mathbf{I I}}$, in Fig. 4c, the $\mathrm{Np}^{4+}$ ion is coordinated to two DGA units and four monodentate nitrate ions leading to a nona-coordinated metal ion, whereas in Fig. 4 d, the $\mathrm{Np}^{4+}$ ion is coordinated to one DGA unit and four nitrate ions (three monodentate and one bidentate) leading to an octa-coordinated metal ion. Similar structural information was obtained for the $\mathrm{Pu}^{4+}$ complexes (Fig. S5 and Table S3, ESI $\dagger$ ).

Thermodynamical free energy of complexation. The free energy for the complexation of the $\mathrm{Np}^{4+}$ ion with $\mathbf{L}_{\mathbf{I}}$ and $\mathbf{L}_{\mathbf{I I}}$, respectively, both in the gas phase and the solution phase is presented in Table 5. The well-known COSMO solvation approach was used to simulate the solvent phase as it is able to predict the solvent phase properties quite accurately. The gas phase free energy was seen to be reduced considerably due to the dielectric screening of the solution phase. The gas phase binding energy of complexation for $\mathbf{L}_{\mathbf{I I}}$ was found to be higher than for $\mathbf{L}_{\mathbf{I}}$. Further, the complexation energy was found to be higher for monodentate nitrate ion over bidentate nitrate ion. In the case of the solution phase, the binding energy of complexation for $\mathbf{L}_{\mathbf{I}}$ was found to be higher than for $\mathbf{L}_{\mathbf{I I}}$ for monodentate nitrate, whereas, the opposite trend is seen in the case of bidentate nitrate. The Gibbs free energy of complexation for $\mathbf{L}_{\mathbf{I I}}$ was found to be higher than that for $\mathbf{L}_{\mathbf{I}}$ as observed in the case of the binding energy. Further, the complexation free energy was found to be higher for monodentate nitrate ion over bidentate nitrate ion. In the case of the solution phase, the binding energy of complexation for $\mathbf{L}_{\mathbf{I I}}$ was found to be higher than for $\mathbf{L}_{\mathbf{I}}$ for bidentate nitrate, whereas, the opposite trend was seen in the case of monodentate nitrate. Overall, the solution phase free energy of complexation of $\mathrm{Np}^{4+}$ for $\mathbf{L}_{\text {II }}$ was higher than that of $\mathbf{L}_{\mathbf{I}}$. In order to compare the preferable complexation between $\mathrm{Np}^{4+}$ and $\mathrm{Pu}^{4+}$ ions, the binding energy of the $\mathrm{Pu}^{4+}$ ion with the $\mathbf{L}_{\mathbf{I}}$ and $\mathbf{L}_{\mathbf{I I}}$ ligands in both the gas and solution phases was determined and the calculated results are listed in Table 5 . The binding energy of the $\mathrm{Pu}^{4+}$ ion with the DGA groups of $\mathbf{L}_{\mathbf{I}}$ and $\mathbf{L}_{\mathbf{I I}}$ in both the gas and solution phases was seen to be higher than that with the $\mathrm{Np}^{4+}$ ion as observed in the experiment. 

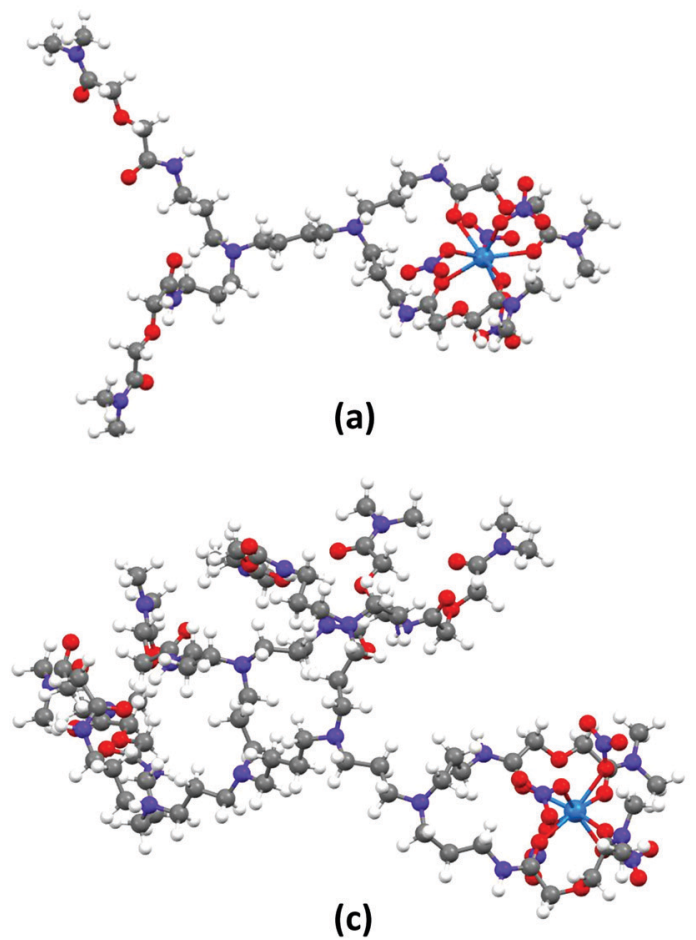

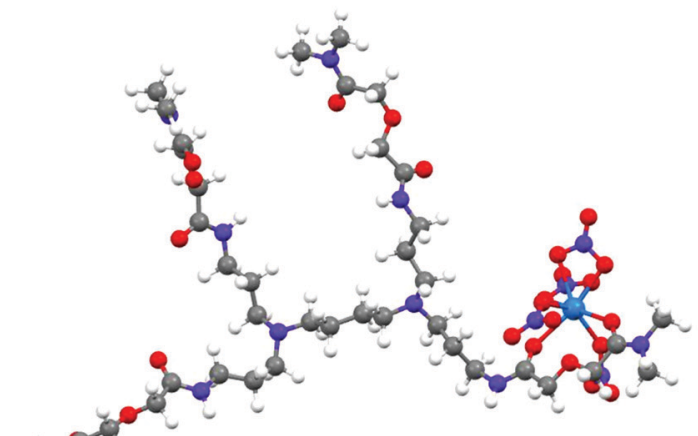

(b)

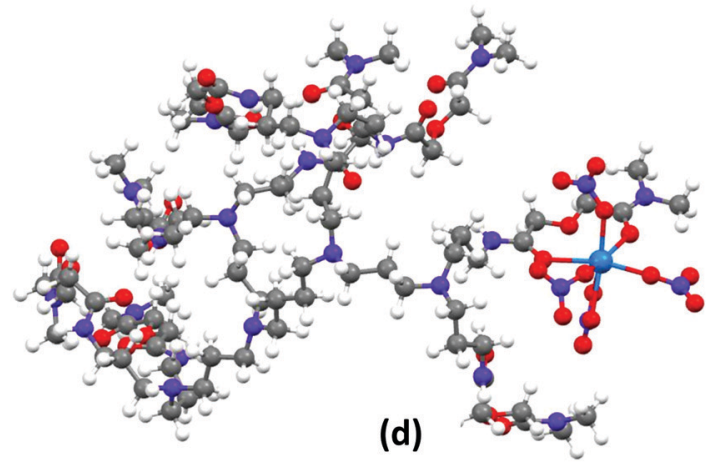

Fig. 4 Optimized structures of complexes of $\mathbf{L}_{1}$ and $\mathbf{L}_{\|}$with $\mathrm{Np}^{4+}$ at the B3LYP/SVP level of theory. (a) The Np ${ }^{4+}$ ion is coordinated to two DGA units and four monodentate nitrate ions; (b) the $\mathrm{Np}^{4+}$ ion is coordinated to one DGA unit and two monodentate and two bidentate nitrate ions; (c) the $\mathrm{Np}^{4+}$ ion is coordinated to two DGA units and four monodentate nitrate ions; and (d) the $\mathrm{Np}^{4+}$ ion is coordinated to one DGA unit and three monodentate and one bidentate nitrate ions. Grey: C, purple: $\mathrm{N}$, red: O, white: $\mathrm{H}$, blue: $\mathrm{Np}$.

Table 4 Calculated structural parameters in $\AA$ at the B3LYP level of theory using the SVP basis set

\begin{tabular}{|c|c|c|c|}
\hline \multicolumn{4}{|l|}{ System } \\
\hline & $\mathrm{Np}-\mathrm{O}(\AA)$ & Np-O (̊̊) & Np-O (̊) \\
\hline \multicolumn{4}{|l|}{$\mathbf{L}_{\mathbf{I}}$} \\
\hline Two nitrate ions as monodentate and two as bidentate & $2.396,2.413$ & 2.774 & $2.244,2.282,2.408,2.434,2.405,2.423$ \\
\hline \multicolumn{4}{|l|}{$\mathbf{L}_{\mathbf{I I}}$} \\
\hline Three nitrate ions as monodentate and one as bidentate & $2.374,2.402$ & 2.733 & $2.179,2.213,2.260,2.439,2.444$ \\
\hline
\end{tabular}

Table 5 Calculated values of the interaction energy $(\mathrm{kcal} / \mathrm{mol})$ for $\mathrm{Np}^{4+}$ complexation in gas and $n$-dodecane phases at the B3LYP level of theory using the SVP basis set. The $\mathrm{Pu}^{4+}$ data are given in parentheses

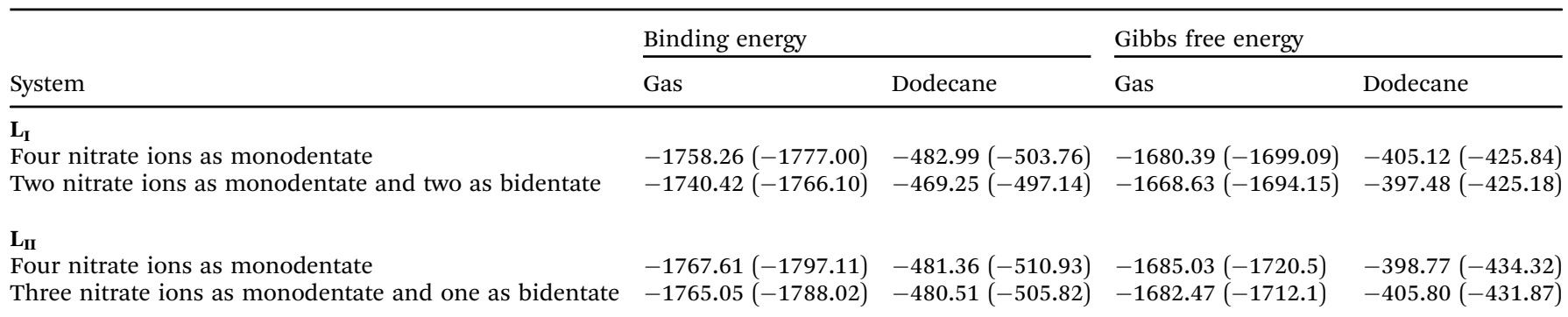


Table 6 Calculated charge and orbital population using NBO analysis in the gas phase at the B3LYP/SVP level of theory

\begin{tabular}{|c|c|c|c|c|c|}
\hline System & Charge & $\mathrm{s}$ & $\mathrm{p}$ & $\mathrm{d}$ & $\mathrm{f}$ \\
\hline Four nitrate ions as monodentate & 1.581 & 4.19 & 11.97 & 11.10 & 4.14 \\
\hline Two nitrate ions as monodentate and two as bidentate & 1.675 & 4.18 & 11.97 & 11.04 & 4.10 \\
\hline \multicolumn{6}{|l|}{$\mathbf{L}_{\text {II }}$} \\
\hline Four nitrate ions as monodentate & 1.692 & 4.18 & 11.96 & 11.07 & 4.07 \\
\hline Three nitrate ions as monodentate and one as bidentate & 1.808 & 4.16 & 11.96 & 11.00 & 4.05 \\
\hline
\end{tabular}

Bonding analysis. To gain insight into the nature of the bonding in the complexes of actinide ions with the DGA-dendrimers $\mathbf{L}_{\mathbf{I}}$ and $\mathbf{L}_{\text {II }}$, the charge on the metal ions and the atomic orbital population in the complexes were analyzed using the method of natural population analysis (NPA). ${ }^{32}$ The calculated values are presented in Table 6. The substantial positive charge on the $\mathrm{Np}$ (Iv) ion indicates an ion-dipole type of interaction in both cases. From NPA, it is revealed that there is a small extra orbital contribution to the inner s, and f subshells and a significant contribution in the $\mathrm{d}$ subshells of the metal ion, indicating that the interaction of the metal ion with the ligand has some covalent character. The $\mathrm{d}$ subshells were found to be more diffused than the $s$ and $f$ subshells. A similar bonding pattern was also observed with the $\mathrm{Pu}$ ion complexes (Table S4, ESI $\dagger$ ).

\section{Conclusions}

The extraction of tetravalent actinide ions viz. $\mathrm{Np}^{4+}$ and $\mathrm{Pu}^{4+}$ was carried out from nitric acid solutions using the diglycolamide-functionalized poly(propylene imine) diaminobutane dendrimers $\mathbf{L}_{\mathbf{I}}$ and $\mathbf{L}_{\mathbf{I I}}$ in a diluent mixture containing $5 \%$ isodecanol and 95\% $n$-dodecane. The organic phase found to extract ca. $1 \%$ nitric acid from $3 \mathrm{M} \mathrm{HNO}_{3}$ and the $K_{\mathrm{H}}$ values of the ligands $\mathbf{L}_{\mathbf{I}}$ and $\mathbf{L}_{\mathbf{I I}}$ were determined to be $0.27( \pm 0.05)$ and $0.32( \pm 0.06)$. The extraction of the metal ions was found to be highly efficient as almost $90 \%$ or higher extraction of the metal ions was observed at $3 \mathrm{M} \mathrm{HNO}_{3}$ using very dilute $\left(1 \times 10^{-4} \mathrm{M}\right)$ ligand solutions. In general, the extraction with $\mathbf{L}_{\mathbf{I I}}$ was higher than that observed with $\mathbf{L}_{\mathbf{I}}$ which was attributed to the higher hydrophobicity of the latter, while Pu(Iv) extraction was higher than that of $\mathrm{Np}(\mathrm{Iv})$, suggesting that the DGA-functionalized dendrimers to be one of the most efficient extractants of the tetravalent actinides reported so far.

The extracted species conformed to $\mathrm{M}\left(\mathrm{NO}_{3}\right)_{4} \mathrm{~L}$ for both $\mathrm{Np}(\mathrm{Iv})$ and $\mathrm{Pu}(\mathrm{Iv})$ with some contributions of $\mathrm{M}\left(\mathrm{NO}_{3}\right)_{4} \cdot 2 \mathrm{~L}$ for $\mathrm{Pu}(\mathrm{IV})$. As it was difficult to explain the bonding of the rather small tetravalent actinide ions (i.r. of Pu(Iv): $0.96 \AA$ A; i.r. of $\mathrm{Np}$ (Iv): $0.98 \AA)^{33}$ with so many DGA functional groups, it was attempted using DFT.

The gas phase as well as the solvent phase free energy of complexation for $\mathrm{Np}^{4+}$ as well as for $\mathrm{Pu}^{4+}$ ions, calculated using hybrid DFT, for $\mathbf{L}_{\mathbf{I}} / \mathbf{L}_{\text {II }}$ was found to be always higher than that of the corresponding complexes as observed in the experiments. The free energy of complexation of $\mathrm{Pu}^{4+}$ ions with $\mathbf{L}_{\mathbf{I}}$ and $\mathbf{L}_{\mathbf{I I}}$ in both the gas and solution phases was seen to be higher than that of with $\mathrm{Np}^{4+}$ ions as observed in the experiment. Different bonding analysis indicates the electrostatic and small covalent nature of the interactions between the metal ions and the chelating DGA-containing dendritic ligands.

Finally, the DGA-functionalized dendrimer ligands may be used for the extraction of tetra-valent ions from radioactive feeds where they may also extract the trivalent actinide ions albeit to a lower extent. ${ }^{14}$ The extraction of $\mathrm{U}(\mathrm{vI})$ was however reported to be insignificant.

\section{Experimental}

\section{Materials}

DGA-functionalized poly(propylene imine) diaminobutane dendrimers $\mathbf{L}_{\mathbf{I}}$ (Gen I) and $\mathbf{L}_{\mathbf{I I}}$ (Gen II) were prepared as described previously. ${ }^{14}$ The purity of the ligands was checked with NMR spectroscopy and HR-MS. The diluents $n$-dodecane and isodecanol (IDA) ( $>99 \%$ purity) were obtained from Lancaster, UK, and SRL, Mumbai, respectively, and were used as obtained. The nitric acid solutions were prepared from Suprapur nitric Acid (Merck, Germany) and Milli Q water (Millipore) and were standardized using a conventional acidbase titrimetric method using AR grade $\mathrm{NaOH}(\mathrm{BDH})$ with phenolphthalein (Fluka, Switzerland) as the indicator.

\section{Radiotracer}

$\mathrm{Pu}$ (mainly ${ }^{239} \mathrm{Pu}$ ) was purified by loading a known amount of $\mathrm{Pu}$ in $8 \mathrm{M} \mathrm{HNO}_{3}$ at Dowex $1 \times 8$ anion exchange resin, followed by its elution with $0.5 \mathrm{M} \mathrm{HNO}_{3}$. The purity of the eluted $\mathrm{Pu}$ sample was checked by alpha as well as gamma ray spectrometry. ${ }^{239} \mathrm{~Np}$ was purified from a neutron irradiated uranyl nitrate hexa hydrate target by extracting it, after adjusting the $\mathrm{Np}$ valency to $\mathrm{Np}$ (Iv) (vide infra), with $0.5 \mathrm{M}$ TTA (2-thenoyltrifluoroacetone; Sigma-Aldrich) in xylene at $1 \mathrm{M}$ $\mathrm{HNO}_{3}$, and subsequent stripping by $8 \mathrm{M} \mathrm{HNO}_{3}$. The aqueous solution was washed several times with xylene to remove any traces of the organic solvent. The purity of the ${ }^{239} \mathrm{~Np}$ was checked by alpha as well as gamma ray spectrometry.

\section{Oxidation state adjustment}

Neptunium(Iv). A solution of ferrous sulfamate solution (0.3 M) was freshly prepared by dissolving a known amount of iron powder (BDH) in sulfamic acid (Aldrich). The resultant $\mathrm{Fe}(\mathrm{II})$ sulfamate solution was used along with a few drops of hydroxylamine nitrate $(1 \mathrm{M})$ as the reductant for the conversion of $\mathrm{Np}$ to its +4 state. The oxidation state of $\mathrm{Np}$ in the stock solution was confirmed intermittently by TTA extraction (ESI $\dagger$ ). 
Plutonium(Iv). The oxidation state of Pu was also adjusted to the +4 state using a $0.05 \mathrm{M}$ solution of $\mathrm{NaNO}_{2}$ (Merck). Details of the oxidation state adjustment are given in the ESI. $\dagger$ Ammonium metavanadate (Aldrich) was used as the holding oxidant for $\mathrm{Pu}(\mathrm{Iv})$ stabilization.

\section{Distribution studies}

Stock solutions of ligands $\mathbf{L}_{\mathbf{I}}$ and $\mathbf{L}_{\mathbf{I I}}$ were prepared by dissolving a known amount of the ligands in 95\% $n$-dodecane $+5 \%$ isodecanol. Appropriate dilutions were made as per the experimental requirements. The distribution ratios $(D)$ of $\mathrm{Np}(\mathrm{Iv})$ and $\mathrm{Pu}(\mathrm{Iv})$ were measured by equilibrating equal volumes (usually $1 \mathrm{~mL}$ ) of ligand solution in 5\% IDA $+n$-dodecane with an aqueous solution containing ${ }^{239} \mathrm{~Np}\left(c a \cdot 10^{-12} \mathrm{M}\right)$ and ${ }^{239} \mathrm{Pu}\left(c a \cdot 10^{-6} \mathrm{M}\right)$ in $5 \mathrm{~mL}$ stoppered glass centrifuge tubes for the required time in a constant temperature $\left(25 \pm 0.1{ }^{\circ} \mathrm{C}\right)$ water bath. The tubes were taken out and centrifuged at $3000 \mathrm{rpm}$ for $5 \mathrm{~min}$ to get well separated aqueous and organic phases. Fixed volumes of both phases $\left(50 \mu \mathrm{L}\right.$ for ${ }^{239} \mathrm{Pu}$ LSC and $100 \mu \mathrm{L}$ for ${ }^{239} \mathrm{~Np} \gamma$-counting) were removed and assayed radiometrically. A toluene-based scintillator containing $10 \%$ di-(2-ethylhexyl)phosphoric acid (HD2EHP) was used for the $\alpha$-counting of ${ }^{239} \mathrm{Pu}$ samples and a well type $\mathrm{NaI}(\mathrm{Tl})$ detector coupled with a multichannel analyzer was used for $\gamma$-counting of ${ }^{239} \mathrm{~Np}$. The $D$ values were determined from the ratio of the activity per minute per unit volume of the organic phase to that in the aqueous phase. The extraction experiments were carried out in duplicate and the reported values are average values with an error of $\leq 5 \%$.

\section{ATR-FTIR studies}

The ATR-FTIR of the $\mathbf{L}_{\mathbf{I}} / \mathbf{L}_{\text {II }}$ dissolved in $5 \%$ isodecanol $+95 \%$ n-dodecane were recorded using a mono reflection ALPHA ATR-FTIR spectrophotometer (Bruker) with a monolithic diamond crystal. All spectra were obtained using a resolution of $4 \mathrm{~cm}^{-1}$ (wave number) under similar measurement conditions (3900-450 $\left.\mathrm{cm}^{-1}\right)$. The presented ATR-FTIR is the average of at least 100 scans and used for the quantitative analysis of free and nitric acid bound $\mathbf{L}_{\mathbf{I}} / \mathbf{L}_{\mathbf{I I}}$ complex in $5 \%$ isodecanol $+95 \%$ $n$-dodecane.

\section{Temperature variation studies}

The stock solutions of the ligands at an appropriate concentration and $\mathrm{HNO}_{3}$ concentration were kept at the desired temperature for at least $30 \mathrm{~min}$ before the beginning of the temperature variation studies. The valency of $\mathrm{Np}$ and $\mathrm{Pu}$ was adjusted prior to the organic phase addition. Equal volumes of the aqueous and organic phases were added in $5 \mathrm{~mL}$ stoppered glass centrifuge tubes and equilibrated for 60 minutes at different temperatures using a temperature controlled $\left( \pm 0.1{ }^{\circ} \mathrm{C}\right)$ water bath. The tubes were taken out and quickly, to avoid any temperature variation, centrifuged at $3000 \mathrm{rpm}$ for $1 \mathrm{~min}$ to get well separated aqueous and organic phases. The aqueous and organic phase activities were analyzed as described above.

\section{Computational methodology}

The structures of the free ligands $\mathbf{L}_{\mathbf{I}}$ and $\mathbf{L}_{\mathbf{I I}}$ and their complexes with $\mathrm{M}^{4+}(\mathrm{M}=\mathrm{Np}$ or $\mathrm{Pu})$ ion the in presence of nitrate ions were optimized using the Becke-Lee-Young-Parr (B3LYP) density functional $^{34}$ employing the split-valence plus polarization (SVP) basis set ${ }^{35}$ as implemented in the TURBOMOLE suite of programs. ${ }^{36}$ The scalar relativistic effective core potentials (ECP) were used for both the $\mathrm{Np}^{4+}$ and $\mathrm{Pu}^{4+}$ ions, where 60 electrons were kept in the core for $\mathrm{Np}$ and $\mathrm{Pu}^{37}$ The quartet spin state was used during the computation of structure and energy. Optimization was performed without any symmetry restrictions. The free energy was computed at $298.15 \mathrm{~K}$ using the B3LYP functional. ${ }^{34}$ The hybrid B3LYP functional has been shown to be quite successful in predicting the thermodynamic properties of actinides. ${ }^{38}$ The solvent phase was accounted for using a popular conductor like the screening model COSMO. ${ }^{39}$ The dielectric constant of $n$-dodecane was taken to be 2 . The model complexation reaction was used as follows:

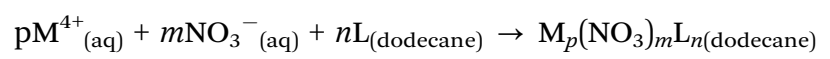

where, $\mathrm{M}=\mathrm{Np}$ or $\mathrm{Pu}$.

The free energy of extraction, $\Delta G_{\text {ext }}$, for the above complexation reaction was evaluated using our earlier reported thermodynamic procedure. $^{40}$

Scalar relativistic effects for heavier lanthanide and actinide elements were included in the present computation using an earlier reported procedure. ${ }^{41}$ Since there is a very small effect on the solvation energy between the gas phase and the solvent phase geometry, ${ }^{42}$ the aqueous solvent effect was integrated by performing single point energy calculations using the optimized geometry obtained from the B3LYP level of theory employing the COSMO solvation model.

\section{Conflicts of interest}

There are no conflicts to declare.

\section{Acknowledgements}

The Computer division at BARC is acknowledged for providing the Anupam supercomputing facility. The authors (PKV, RBG and PKM) sincerely acknowledge Dr P. K. Pujari, Director, RC\&IG and (SMA) Mr K. T. Shenoy, Associate Director, ChEG for continuous encouragement.

\section{References}

1 S. A. Ansari, P. N. Pathak, P. K. Mohapatra and V. K. Manchanda, Chem. Rev., 2012, 112, 1751-1772.

2 (a) J. N. Mathur, M. S. Murali and K. L. Nash, Solvent Extr. Ion Exch., 2001, 19, 357-390; (b) S. A. Ansari, P. Pathak, P. K. Mohapatra and V. K. Manchanda, Sep. Purif. Rev., 2011, 40, 43-76; (c) B. Christiansen, C. Apostolidis, R. Carlos, O. Courson, J.-P. Glatz, R. Malmbeck, G. Pagliosa, 
K. Römer and D. Serrano-Purroy, Radiochim. Acta, 2004, 92, 475-480.

3 M. I. Ojovan and W. E. Lee, An Introduction to Nuclear Waste Immobilisation, Elsevier, Amsterdam, 2005.

4 (a) Y. Sasaki, Y. Sugo, S. Suzuki and S. Tachimori, Solvent Extr. Ion Exch., 2001, 19, 91-103; (b) R. B. Gujar, S. A. Ansari, P. K. Mohapatra, M. S. Murali and V. K. Manchanda, J. Radioanal. Nucl. Chem., 2010, 284, 377-385; (c) S. A. Ansari, P. N. Pathak, V. K. Manchanda, M. Hussain, A. Prasad and V. S. Parmar, Solvent Extr. Ion Exch., 2005, 23, 463-479.

5 (a) W. Schulz and E. P. Horwitz, Sep. Sci. Technol., 1988, 23, 1191-1210; (b) E. P. Horwitz and D. G. Kalina, Solvent Extr. Ion Exch., 1984, 2, 179-200.

6 Y. Morita, J.-P. Glatz, M. Kubota, L. Koch, G. Pagliosa, K. Roemer and A. Nicholl, Solvent Extr. Ion Exch., 1996, 14, 385-400.

7 Y. Zhu and R. Jiao, Nucl. Technol., 1994, 108, 361-369.

8 (a) D. Serrano-Purroy, B. Christiansen, R. Malmbeck, J. P. Glatz and P. Baron, Partitioning of minor actinides from HLW using DIAMEX Process, Proc. Global, New Orleans, USA, 2003; (b) D. Serrano-Purroy, P. Baron, B. Christiansen, R. Malmbeck, C. Sorel and J.-P. Glatz, Radiochim. Acta, 2005, 93, 351-355.

9 (a) G. Modolo, G. Asp, C. Schreinemachers and H. Vijgen, Solvent Extr. Ion Exch., 2007, 25, 703-721; (b) S. A. Ansari, D. R. Prabhu, R. B. Gujar, A. S. Kanekar, B. Rajeswari, M. J. Kulkarni, M. S. Murali, Y. Babu, V. Natarajan, S. Rajeswari, A. Suresh, R. Manivannan, M. P. Antony, T. G. Srinivasan and V. K. Manchanda, Sep. Purif. Technol., 2009, 66, 118-124; (c) R. B. Gujar, S. A. Ansari, D. R. Prabhu, P. N. Pathak, A. Sengupta, S. K. Thulasidas, P. K. Mohapatra and V. K. Manchanda, Solvent Extr. Ion Exch., 2012, 30, 156-170.

10 (a) P. K. Mohapatra, M. Iqbal, D. R. Raut, W. Verboom, J. Huskens and S. V. Godbole, Dalton Trans., 2012, 41, 360-363; (b) P. K. Mohapatra, A. Sengupta, M. Iqbal, J. Huskens and W. Verboom, Inorg. Chem., 2013, 52, 2533-2541.

11 (a) L. Wu, Y. Fang, Y. Jia, Y. Yang, J. Liao, N. Liu, X. Yang, W. Feng, J. Ming and L. Yuan, Dalton Trans., 2014, 43, 3835-3838; (b) C. Li, L. Wu, L. Chen, X. Yuan, Y. Cai, W. Feng, N. Liu, Y. Ren, A. Sengupta, M. S. Murali, P. K. Mohapatra, G. Tao, H. Zeng, S. Ding and L. Yuan, Dalton Trans., 2016, 45, 19299-19310.

12 A. Leoncini, P. K. Mohapatra, A. Bhattacharyya, D. R. Raut, A. Sengupta, P. K. Verma, N. Tiwari, D. Bhattacharyya, S. Jha, A. M. Wouda, J. Huskens and W. Verboom, Dalton Trans., 2016, 45, 2476-2484.

13 A. Leoncini, S. A. Ansari, P. K. Mohapatra, A. Boda, Sk. M. Ali, A. Sengupta, J. Huskens and W. Verboom, Dalton Trans., 2017, 46, 1431-1438.

14 A. Leoncini, S. A. Ansari, P. K. Mohapatra, A. Sengupta, J. Huskens and W. Verboom, Dalton Trans., 2017, 46, 501-508.

15 C. Madic, M. J. Hudson, J. O. Liljenzin, J.-P. Glatz, R. Nannicini, A. Facchini, Z. Kolarik and Z. R. Odoj, New
Partitioning Techniques for Minor Actinides, EUR 19149, European Commission, Luxembourg, 2000, p. 59.

16 S. S. Kapoor, Pramana, 2002, 59, 941-950.

17 A. Witze, Nature, 2014, 515, 484-486.

18 A. Kumar, P. K. Mohapatra, P. N. Pathak and V. K. Manchanda, Talanta, 1997, 45, 387-395.

19 S. Guoxin, L. Min, C. Yu, Y. Meilong and Y. Shaohong, Solvent Extr. Ion Exch., 2010, 28, 482-494.

20 J. Ravi, A. S. Suneesh, T. Prathibha, K. A. Venkatesan, M. P. Antony, T. G. Srinivasan and P. R. Vasudeva Rao, Solvent Extr. Ion Exch., 2011, 29, 86-105.

21 Z. Yoshida, S. G. Johnson, T. Kimura and J. R. Krsul, in The Chemistry of the actinide and trans-actinide elements, ed. L. R. Morss, N. M. Edelstein, J. Fuger and J. J. Katz, Springer, Dordrecht, The Netherlands, 3rd edn, 2006, vol. 2, p. 768.

22 B. Mahanty, A. Bhattacharyya, A. S. Kanekar and P. K. Mohapatra, Solvent Extr. Ion Exch., 2020, 38, 290-303.

23 W. J. Hamer and Y. C. Wu, J. Phys. Chem. Ref. Data, 1972, 1, 1047-1100.

24 M. der Mar Marcos-Arroyo, M. K. Khoshkbarchi and J. H. Vera, J. Solution Chem., 1996, 25, 983-1000.

25 W. Davis Jr and H. De Bruin, J. Inorg. Nucl. Chem., 1964, 26, 1069-1083.

26 S. Bagawde, P. R. V. Rao, V. V. Ramakrishna and S. K. Patil, J. Inorg. Nucl. Chem., 1978, 40, 1913-1918.

27 T. Srinivasan, P. Vasudeva Rao and D. Sood, Solvent Extr. Ion Exch., 1997, 15, 15-31.

28 S. K. Patil, V. Ramakrishna, G. Avadhany and M. Ramaniah, J. Inorg. Nucl. Chem., 1973, 35, 2537-2545.

29 S. Bagawde, V. V. Ramakrishna and S. K. Patil, J. Inorg. Nucl. Chem., 1976, 38, 1339-1345.

30 S. K. Patil, V. V. Ramakrishna and M. V. Ramaniah, Coord. Chem. Rev., 1978, 25, 133-171.

31 J. Brothers, R. Hart and W. Mathers, J. Inorg. Nucl. Chem., 1958, 7, 85-93.

32 (a) A. E. Reed and F. Weinhold, J. Chem. Phys., 1983, 78, 4066-4073; (b) A. E. Reed, R. B. Weinstock and F. Weinhold, J. Chem. Phys., 1985, 83, 735-746; (c) A. E. Reed, L. A. Curtiss and F. Weinhold, Chem. Rev., 1988, 88, 899-926.

33 R. D. Shannon, Acta Crystallogr., Sect. A: Cryst. Phys., Diffr., Theor. Gen. Crystallogr., 1976, 32, 751-767.

34 (a) A. D. Becke, J. Chem. Phys., 1993, 98, 5648-5652; (b) C. Lee, W. Wang and R. G. Parr, Phys. Rev. B: Condens. Matter Mater. Phys., 1988, 37, 785-789.

35 A. Schaefer, H. Horn and R. J. Ahlrichs, J. Chem. Phys., 1992, 97, 2751-2777.

36 (a) R. Ahlrichs, M. Bär, M. Häser, H. Horn and C. Kölmel, Chem. Phys. Lett., 1989, 162, 165-169; (b) TURBOMOLE V6.0 2009, a development of University of Karlsruhe and Forschungszentrum Karlsruhe GmbH, TURBOMOLE GmbH, 1989-2007.

37 (a) M. Dolg, H. Stoll and H. Preuss, J. Chem. Phys., 1989, 90, 1730-1734; (b) W. Kuchle, M. Dolg, H. Stoll and H. Preuss, J. Chem. Phys., 1994, 100, 7535-7542; (c) X. Cao and M. Dolg, THEOCHEM, 2004, 673, 203-209; (d) X. Cao and M. Dolg, THEOCHEM, 2002, 581, 139-147. 
38 A. Klamt, J. Phys. Chem., 1995, 99, 2224-2235.

39 G. A. Shamov, G. Schreckenbach and T. N. Vo, Chem. - Eur. J., 2007, 13, 4932-4947.

40 (a) Sk. M. Ali, J. M. Joshi, A. K. Singha Deb, A. Boda, K. T. Shenoy and S. K. Ghosh, RSC Adv., 2014, 4, 22911-22925; (b) Sk. M. Ali, Comput. Theor. Chem., 2014, 1034, 38-52; (c) Sk. M. Ali, Eur. J. Inorg. Chem., 2014, 1533; (d) S. Pahan, A. Boda and Sk. M. Ali, Theor. Chem. Acc., 2015, 134, 41-57.

41 (a) C. Z. Wang, J. H. Lan, Q. Y. Wu, Y. L. Zhao, X. K. Wang, Z. F. Chai and W. Q. Shi, Dalton Trans., 2014, 43, 8713-8720; (b) J. P. Austin, M. Sundararajan, M. A. Vincent and I. H. Hiller, Dalton Trans., 2009, 5902-5909; (c) D. Manna and T. K. Ghanty, Phys. Chem. Chem. Phys., 2012, 14, 11060-11069.

42 (a) G. A. Shamov and G. Schreckenbach, J. Phys. Chem. A, 2005, 109, 10961-10974; (b) A. Boda, J. M. Joshi, Sk. M. Ali, K. T. Shenoy and S. K. Ghosh, J. Mol. Model., 2012, 19, 5277-5291; (c) A. Boda, Sk. M. Ali, K. T. Shenoy and S. K. Ghosh, Sep. Sci. Technol., 2013, 48, 2397-2409. 